\title{
O ensino remoto como ferramenta para a discussão da temática compostos plásticos em uma turma do primeiro ano do Ensino Médio
}

\author{
Remote education as a tool for discussing the thematic plastic compounds in a classe of the first \\ year of High School \\ La educación a distancia como herramienta de discusión de los compuestos plásticos temáticos en \\ una clase del primer curso de Bachillerato
}

Recebido: 16/07/2021 | Revisado: 20/07/2021 | Aceito: 22/07/2021 | Publicado: 30/07/2021

\author{
Mariana Nascimento Bringel \\ ORCID: https://orcid.org/0000-0002-6992-1030 \\ Instituto Federal de Educação, Ciência e Tecnologia do Piauí, Brasil \\ E-mail: mnbringel@gmail.com \\ Daniela Pereira Araújo \\ ORCID: https://orcid.org/0000-0003-2438-6764 \\ Instituto Federal de Educação, Ciência e Tecnologia do Piauí, Brasil \\ E-mail:daniela.araujo971s@gmail.com/ \\ Ícaro Fillipe de Araújo Castro \\ ORCID: https://orcid.org/0000-0003-1808-9157 \\ Instituto Federal de Educação, Ciência e Tecnologia do Piaú, Brasil \\ E-mail: icaro.castro@ifpi.edu.br
}

\begin{abstract}
Resumo
Grande parte dos produtos gerados a partir dos plásticos são imediatamente descartados, pouco reciclados e lentamente decompostos, destacando-se a Educação Ambiental como uma ferramenta de sensibilização frente aos problemas associados a esses compostos. Por isso, esse trabalho teve como objetivo estimular o conhecimento de discentes do primeiro ano do Ensino Médio ao uso seguro das embalagens plásticas e seus riscos associados ao meio ambiente e à saúde humana. Por serem menores de idade, a participação exigiu um Termo de Responsabilidade assinado pelos responsáveis legais dos discentes. Inicialmente, os alunos responderam ao questionário que buscava avaliar o contexto da Educação Ambiental na Educação Básica de Uruçuí-PI, e conhecimentos dos discentes para a temática. Posteriormente, foram realizados dois encontros por meio da ferramenta Google Meet, com debates pertinentes ao tema. Após cada encontro, realizou-se um novo questionário para estimar a sua influência no aprendizado dos alunos. Utilizouse a ferramenta Google Forms para confeccionar os formulários e seu envio ocorreu pelo aplicativo WhatsApp. A partir das respostas, observamos que a Educação Ambiental foi trabalhada de forma insatisfatória e fragmentada no contexto escolar dos participantes, e que os alunos conhecem alguns problemas associados ao uso de embalagens plásticas, embora demonstrem desconhecimento dos seus riscos à saúde humana e seu maior consumo no cenário pandêmico. Enfatizamos também que as discussões ocorridas de forma remota se mostraram proveitosas e adequadas para o período vivenciado. Apontamos a necessidade da discussão de temas relevantes à Educação Ambiental de forma contextualizada ao cotidiano discente e integrada aos conteúdos escolares.
\end{abstract}

Palavras-chave: Consumo de plásticos; Poluição ambiental; Ensino.

\begin{abstract}
A large part of the products generated from plastics is immediately discarded, little recycled and slowly decomposed, with Environmental Education standing out as a tool to raise awareness of the problems associated with these compounds. Therefore, this work aimed to encourage the knowledge of first year high school students to the safe use of plastic packaging and its risks associated with the environment and human health. As they are minors, participation requires a Term of Responsibility Signed by the students' legal guardians. Initially, the students answered the questionnaire that sought to assess the context of Environmental Education in Basic Education in Uruçuí-PI, and the students' knowledge of the theme. Subsequently, two meetings were held using the Google Meet tool, with debates relevant to the topic. After each meeting, a new questionnaire was administered out to estimate its influence on student learning. Use a Google Forms tool to create the forms and send them through the WhatsApp application. From the answers, we observed that Environmental Education was worked in an unsatisfactory and fragmented way in the school context of the participants, and those students know some problems associated with the use of plastic packaging, although they demonstrate ignorance of its human health risks and its greater consumption in the pandemic scenario. We also emphasize that it occurs when a remote form occurs if it has been tested and compared to the experienced
\end{abstract}


period. We point out the need to discuss topics relevant to Environmental Education in a contextualized way to the student's daily life and integrated with school content.

Keywords: Plastic consumption; Environmental pollution; Teaching.

\section{Resumen}

Una gran parte de los productos generados a partir de plásticos se descartan de inmediato, se reciclan poco y se descomponen lentamente, destacando la Educación Ambiental como una herramienta para concienciar sobre los problemas asociados a estos compuestos. Por ello, este trabajo tuvo como objetivo fomentar el conocimiento de los estudiantes de primer año de secundaria sobre el uso seguro de los envases de plástico y sus riesgos asociados con el medio ambiente yores legales de los estudiantes. Inicialmente, los estudiantes respondieron el cuestionario que buscaba evaluar el contexto de la Educación Ambiental en Educación Básica en Uruçuí-PI, y el conocimiento de los estudiantes sobre el tema. Posteriormente, se realizaron dos reuniones utilizando la herramienta Google Meet, con debates relevantes sobre el tema. Después de cada reunión, se realizó un nuevo cuestionario para estimar su influencia en el aprendizaje de los estudiantes. Utilice una herramienta de Formularios de Google para crear los formularios y enviarlos a través de la aplicación WhatsApp. A partir de las respuestas, observamos que la Educación Ambiental se trabajó de manera insatisfactoria y fragmentada en el contexto escolar de los participantes, y que los estudiantes conocen algunos problemas asociados con el uso de envases plásticos, aunque demuestran desconocimiento de sus riesgos para la salud humana y su mayor consumo en el escenario pandémico. También enfatizamos que ocurre cuando ocurre una forma remota si ha sido probada y comparada con el período experimentado. Señalamos la necesidad de discutir temas relevantes para la Educación Ambiental de manera contextualizada a la vida diaria del alumno e integrada con los contenidos escolares.

Palabras clave: Consumo de plástico; Contaminación ambiental; Enseñanza.

\section{Introdução}

Vivemos um momento de total dependência aos compostos plásticos, que são amplamente utilizados na indústria de transportes, de equipamentos médicos, produtos farmacológicos, alimentos, entre outras, com vantagens associadas a seu custo de produção, durabilidade e aplicabilidade. Araújo \& Silva (2016) relatam que as mesmas vantagens da aplicabilidade dos plásticos, possibilitam e influenciam no seu acúmulo de maneira imprópria nos ambientes naturais, e que o descarte inapropriado desse material tem aumentado de maneira equivalente à velocidade de sua produção.

Embora existam diversas vantagens dos plásticos para a indústria alimentícia e outras demais, o sucesso dos plásticos se dá principalmente pela necessidade de permitir soluções de baixo custo, contudo essas soluções acarretam diversos problemas, tanto tecnológicos e sociais, que se tornam de alto custo principalmente para o meio ambiente (Azeredo et al., 2017).

Diante da problemática ocasionada pela utilização e acúmulo de plásticos, observa-se a necessidade da inserção dessa temática nos conteúdos escolares, principalmente aqueles relacionados à Educação Ambiental. Assim, relacionar tais conteúdos ao cotidiano dos discentes se caracteriza como uma importante ferramenta educativa para compreensão do mundo e para a tomada de decisões.

Carneiro, Oliveira \& Moreira (2016) evidenciam em seu estudo que a escola é um espaço que deve contribuir na formação de cidadãos reflexivos que reconheçam suas responsabilidades e direitos. Giassi et al. (2016), destacam que as instituições de ensino possuem grande impacto na Educação Ambiental, por serem espaços que proporcionam a sensibilização dos alunos diante da tomada de ações conscientes de forma ativa e participativa.

A Lei no 9.795/99, que dispõe sobre a Educação Ambiental e institui a Política Nacional de Educação Ambiental, estabelece em seu 2o artigo que esta é um componente essencial e permanente da Educação Nacional (Brasil, 1999). Além disso, a Constituição Federal destaca a sua obrigatoriedade "em todos os níveis de ensino". Destaca-se também a inclusão do tema meio ambiente nos Parâmetros Curriculares Nacionais do MEC - PCN (Brasil, 1997). Nesse contexto, os PCNs caracterizam a Educação Ambiental como uma questão que exige cuidado e atenção, e alertam para os cuidados que são indispensáveis à manutenção e continuidade da vida no planeta (Menezes et al., 2018).

Para Silva (2019), a Educação Ambiental pode ser apontada como alternativa para trabalhar os riscos à saúde ambiental e humana, uma vez que percebe-se a relevância do cuidado com o meio ambiente não só pela promoção de saúde dos indivíduos, 
como também a dos ecossistemas. Diante disso, Santos et al. (2019) relata que uma das maneiras para provocar modificações das práticas dos indivíduos, para que pratiquem ações mais responsáveis em relação à utilização dos recursos naturais se dá pela educação. Assim, a Educação Ambiental utilizada como ferramenta para debater problemas ocasionados pela utilização de plásticos torna-se efetiva, criando melhorias para os indivíduos através do processo de ensino-aprendizagem.

Pereira, Rohde \& Castro (2020), ao realizarem um trabalho no município de Uruçuí-PI, evidenciaram que a Educação Ambiental não vem sendo trabalhada de forma satisfatória na educação escolar do município e que a temática relacionada ao uso de embalagens plásticas é quase inexistente. Por isso, esse trabalho tem como objetivo estimular o conhecimento de discentes de uma turma do primeiro ano do Ensino Médio ao uso seguro e consciente das embalagens plásticas e seus riscos associados ao meio ambiente e à saúde humana.

\section{Metodologia}

A presente pesquisa caracteriza-se como quali-quantitativa por reunir dados numéricos e concepções dos investigados em relação à temática discutida (Pereira et al., 2018). A escolha do tema em questão se deu pela leitura do trabalho de Pereira, Rohde \& Castro (2020) que evidenciou carências relacionadas ao ensino da Educação Ambiental na Educação Básica de UruçuíPI, principalmente em relação aos conteúdos relacionados ao uso de embalagens plásticas e os riscos associados ao meio ambiente e saúde humana.

Para a realização da pesquisa, inicialmente houve contato com um professor da disciplina de Biologia do Instituto Federal do Piauí, e após sua anuência, discentes do primeiro ano do Ensino Médio de Biologia da Educação Básica do Instituto Federal do Piauí, foram convidados a participar da pesquisa. Todo o contato com o docente e participantes da pesquisa, aconteceu de forma remota, respeitando o isolamento social preconizado pela Organização Mundial de Saúde (OMS).

Para realização do contato, utilizou-se a ferramenta de troca de mensagens on-line WhatsApp. Por meio dela, o públicoalvo foi apresentado aos objetivos da pesquisa e convidado a participar. Por serem todos menores de idade, a inclusão na pesquisa exigia aos participantes concordância a um Termo de Responsabilidade devidamente assinado pelos respectivos responsáveis.

Após a anuência dos participantes e responsáveis, foi aplicado o questionário um baseado no trabalho de Pereira, Rohde \& Castro (2020), composto por 13 questões. As perguntas buscaram avaliar como está ocorrendo a Educação Ambiental na Educação Básica de Uruçuí-PI, bem como as perspectivas de discentes relacionadas a essa temática, com ênfase no estudo das embalagens plásticas. Esse momento de coleta de dados também ocorreu de forma remota, utilizando-se para isso a ferramenta Google Forms e o aplicativo WhatsApp.

O questionário aplicado aos alunos também continha algumas perguntas de vestibulares e ENEM relacionadas à temática embalagens plásticas. Essas perguntas foram novamente aplicadas após a realização do primeiro e segundo encontro com os discentes (via Google Meet) para observação da importância dos encontros remotos realizados na pesquisa para o aprendizado dos alunos. As respostas obtidas anteriormente e posteriormente aos encontros com os participantes foram comparadas por meio da porcentagem de acertos entre elas.

No primeiro encontro, detalhou-se a constituição dos materiais plásticos, sua produção a partir do petróleo, da cana de açúcar (plástico ecológico) e processo de reciclagem, bem como os principais problemas acompanhados ao uso desses componentes. Logo após esse momento, os alunos participantes receberam um formulário via Google Forms com três perguntas, sendo duas objetivas similares às do primeiro questionário e buscavam aferir os conhecimentos dos alunos sobre os compostos plásticos. Além disso, discutiu-se com os discentes a relação entre o aumento no uso de componentes plásticos durante a pandemia e principalmente a diminuição da reciclagem desses compostos.

Três dias após o primeiro encontro, ocorreu o segundo, abordando-se a poluição marinha relacionada ao acúmulo de plásticos nos oceanos e seus impactos aos organismos aquáticos. Discutiu-se ainda sobre os microplásticos, com ênfase aos riscos 
de acumulação nos organismos (bioacumulação) e aumento de concentração ao longo das cadeias tróficas (biomagnificação). Foram ainda apresentados os resultados de 10 artigos científicos que relacionavam a migração de componentes plásticos para água e alimentos, evidenciando sua toxicidade e os riscos à saúde humana.

Logo após, um novo questionário foi aplicado (questionário três) contendo três perguntas, repetindo-se duas já presentes no questionário um e uma pergunta aberta referente aos riscos à saúde humana associada às embalagens plásticas. Posteriormente, os dados foram analisados, e a partir das perguntas objetivas foram descritas o número de respostas e porcentagens nas respostas para cada alternativa. Foram também confeccionados quando necessários gráficos que representavam as respostas dos participantes, utilizando-se para isso o programa Microsoft Excel (2003). Para questões abertas, utilizou-se uma análise de conteúdo voltada à manipulação do texto para interpretação e inferência dos sentidos (Ferreira \& Loguecio, 2014). A representação literal da fala dos participantes ocorreu por meio da confecção de quadros.

\section{Resultados e Discussão}

Participaram da pesquisa 31 alunos do primeiro ano do Ensino Médio, sendo 16 discentes do sexo feminino $(51,6 \%)$ e 15 do sexo masculino (48,4\%). A faixa etária predominante foi composta por alunos entre 15 e 16 anos (96,7\%). Na questão um, perguntou-se aos discentes a frequência na qual a Educação Ambiental era trabalhada no ambiente escolar. Nas respostas, 14 discentes $(45,2 \%)$ responderam que foi trabalhada de forma moderada, oito discentes $(25,8 \%)$ disseram ter sido pouco trabalhada, $7(22,6 \%)$ responderam que foi bem trabalhada, e dois alunos $(6,5 \%)$ apontaram que não foi trabalhada no seu contexto escolar, como evidenciado na Figura 1.

Figura 1: Representação gráfica das respostas dos discentes em relação à frequência da Educação Ambiental no seu contexto escolar.

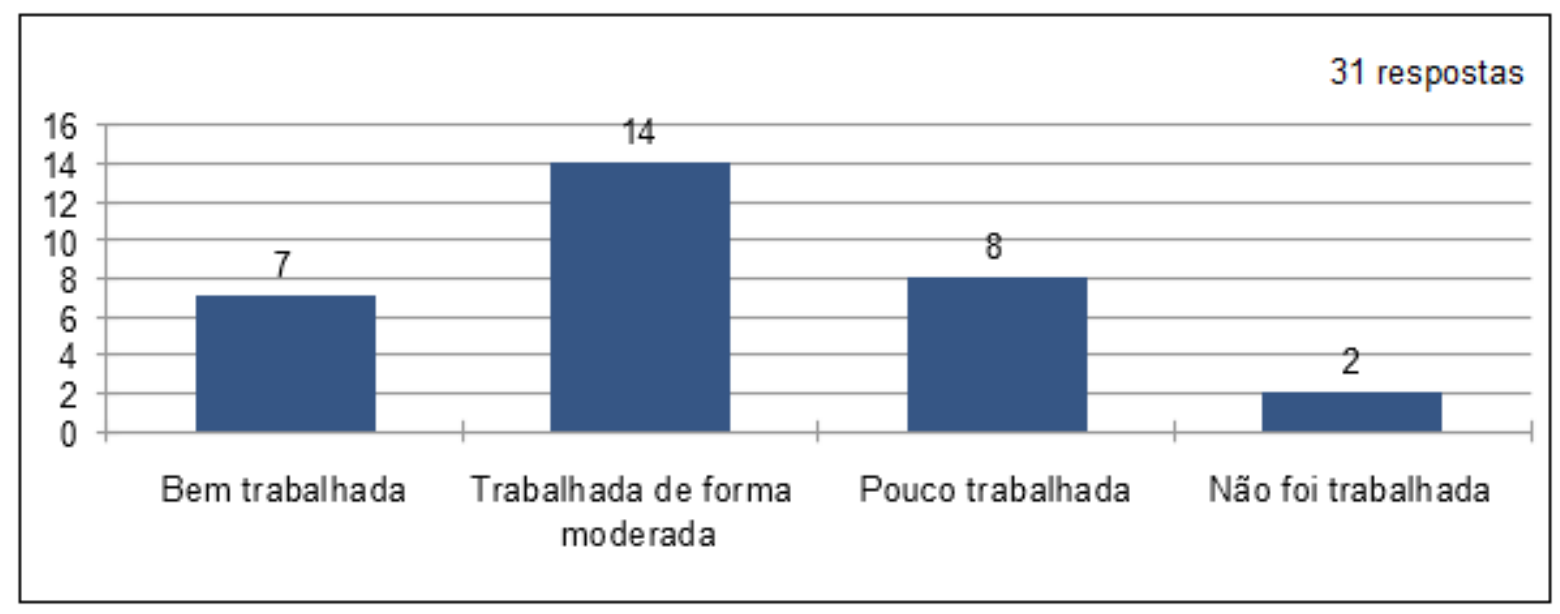

Fonte: Autores (2021).

Observa-se no gráfico que a maioria dos alunos destacam que a Educação Ambiente foi trabalhada de forma moderada ou pouco trabalhada no contexto escolar, o que evidencia carência na formação cidadã relacionada a um tema tão importante e complexo que engloba não só questões relacionadas à saúde humana, mas ao ecossistema em geral. Em relação aos resultados observados, Silva (2019) destaca que a Educação Ambiental continua sendo tratada de forma pouco relevante e em alguns casos nem mesmo é trabalhada nas escolas. Nesse sentido, Pereira, Rohde \& Castro (2020) destacam que a Educação Ambiental precisa ser melhor abordada não somente no ambiente escolar, mas em outros meios e de forma contínua.

Na segunda questão, indagou-se aos participantes o conceito de Educação Ambiental. Nas respostas, 14 alunos (45,2\%) conceituaram o termo de forma correta, evidenciando conhecimento prévio sobre o tema, e 17 alunos $(54,8 \%)$ erraram o conceito 
ou deixaram a alternativa em branco. A transcrição literal de algumas das respostas consideradas corretas para a referida questão podem ser lidas no Quadro 1, evidenciado a seguir.

Quadro 1: Conceitos dos discentes para o termo Educação Ambiental.

\begin{tabular}{|c|l|}
\hline Aluno 1 & $\begin{array}{l}\text { "Educação ambiental é desenvolver nas pessoas a consciência dos problemas } \\
\text { ambientais e estimulá-las a tentar buscar soluções para os problemas." }\end{array}$ \\
\hline Aluno 2 & $\begin{array}{l}\text { "Meio no qual o indivíduo e a coletividade constroem valores sociais, } \\
\text { conhecimentos, habilidades e atitudes para a conservação do meio ambiente. }\end{array}$ \\
\hline Aluno 3 & $\begin{array}{l}\text { "Meio que permite que as pessoas busquem a conservação e preservação do } \\
\text { meio ambiente. }\end{array}$ \\
\hline Aluno 4 & $\begin{array}{l}\text { "A educação ambiental é para ensinar as pessoas a cuidarem do nosso } \\
\text { planeta Terra. }\end{array}$ \\
\hline Aluno 5 & "A educação ambiental é falar sobre os cuidados ao meio ambiente." \\
\hline
\end{tabular}

Fonte: Autores (2021).

Os resultados apontados anteriormente evidenciam dificuldade na formulação de conceitos pelos alunos participantes, ou pouca discussão relacionada à Educação Ambiental. O dado apontado exige reflexão de docentes e instituições de ensino, uma vez que tais conteúdos devem estar inclusos no cotidiano escolar desses alunos desde os anos iniciais de ensino como tema transversal em todas as disciplinas, como exige os Parâmetros Curriculares Nacionais do MEC - PCN (Brasil, 1997).

$\mathrm{Na}$ terceira questão, perguntou-se aos participantes se tinham conhecimento sobre algum projeto de Educação Ambiental desenvolvido na sua escola. Nas respostas, 17 alunos (54,8\%) apontaram não ter conhecimento e 14 alunos (45,2\%) disseram ter conhecimento. As respostas evidenciam que tais projetos em geral são trabalhados de forma fragmentada em certas disciplinas com pouca divulgação.

Para Oliveira \& Amaral (2019), os trabalhos de Educação Ambiental são executados na maioria das vezes apenas por professores da área de Ciências e Biologia e não em todas as disciplinas como é o ideal. Nesse sentido, projetos que explorem os conteúdos de Educação Ambiental nas escolas permitem que os estudantes associem diversos pontos da temática ao seu cotidiano. A realização de tais projetos são imprescindíveis, uma vez que estimula desenvolvimento do raciocínio crítico dos alunos, habilidades na produção de matérias pedagógicas sobre o tema e melhor compreensão de diversos subtemas e conceitos em Educação Ambiental (Pacheco et al., 2020).

$\mathrm{Na}$ pergunta seguinte, investigou-se como a temática dos compostos plásticos foi discutida no ambiente escolar dos participantes. Nas respostas, 13 alunos (41,9\%) apontaram que foi bem discutida, 12 alunos (38,7\%) afirmaram que foi pouco discutida e seis alunos $(19,4 \%)$ disseram que não foi discutida. O pouco ou nenhum contato com o tema apontado por nosso estudo, pode estar associado a déficit na Educação Ambiental, uma vez que para Cruz, Souza \& Freitas (2020), a Educação Ambiental contribui para a redução da problemática dos materiais plásticos que são despejados de forma inapropriada, sendo assim uma maneira de promoção da reflexão acerca do que é correto e errado e dos diversos danos ambientais pela falta de consciência ambiental.

Na questão de número cinco, foi perguntado se os alunos já haviam realizado alguma atividade prática que envolvesse a temática embalagens plásticas na instituição onde estudaram. Dos entrevistados, 19 alunos (61,3\%) afirmam já ter realizado, 
enquanto 12 alunos (38,7\%) disseram que não. Nessa perspectiva, Antqueves, Bosa \& Dubaski-Silva (2015) pontuam a importância da conciliação entre conteúdos relacionados à Educação Ambiental à prática de atividades lúdicas nas escolas, uma vez que esse método de ensino ajuda o aluno a perceber a problemática em seu cotidiano e estimula a sensibilização necessária aos cuidados como o meio ambiente.

Segundo os autores supracitados, esse método de ensino se mostrou muito eficaz após desenvolverem atividades com crianças do Ensino Fundamental. Na atividade proposta, os alunos deveriam observar quais lixos eram por eles produzidos durante o seu dia, bem como a maneira correta de descartá-los. Na atividade, observou-se que as embalagens plásticas utilizadas durante o dia correspondiam a mais da metade desse lixo, o que estimulou a reflexão das crianças e mudança de hábitos frente ao consumo diário de embalagens plásticas (Antqueves et al., 2015).

A questão número seis pedia aos participantes que apontassem o principal problema associados aos compostos plásticos. Nas respostas, 13 alunos apontaram riscos a fauna marinha (41,9\%), 10 participantes $(35,5 \%)$ indicaram contaminação do ambiente, dois discentes $(6,4 \%)$ associaram esses produtos as enchentes, um aluno $(3,2 \%)$ indicou contribuição para o efeito estufa e cinco alunos $(16,1 \%)$ deixaram a questão em branco. Observa-se a partir das respostas que nenhum dos participantes relacionou o uso de embalagens plásticas a riscos à saúde humana, apontando pouco conhecimento dessa relação. As respostas categorizadas podem ser visualizadas na Figura 2.

Figura 2: Representação gráfica das respostas dos discentes em relação aos principais problemas relacionados ao uso das embalagens plásticas.

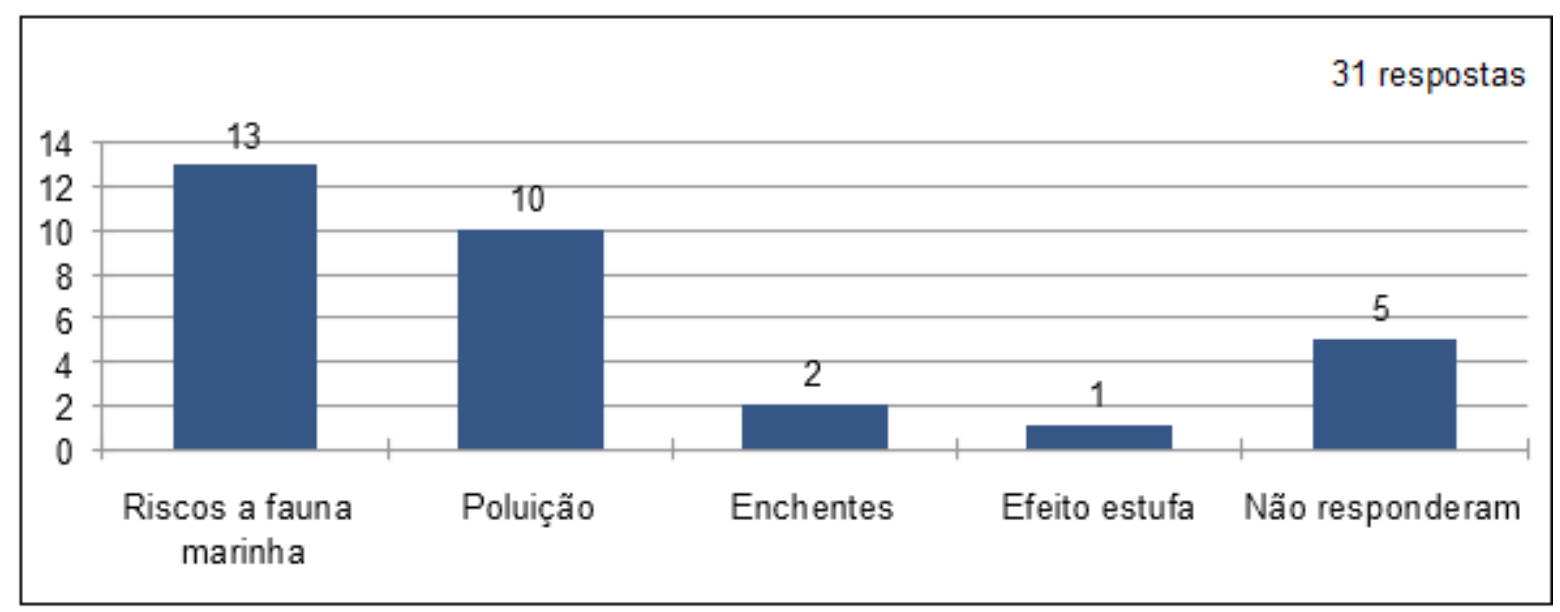

Fonte: Autores (2021).

Na sétima questão, indagou-se aos participantes se utilizam embalagens plásticas para a armazenagem de água e/ou alimentos. Nas respostas, 27 alunos $(87,1 \%)$ afirmaram utilizar, enquanto quatro $(12,9 \%)$ não utilizam. Nesse sentido Azeredo et al. (2017) alerta sobre os riscos ao uso desse tipo de embalagem em contato com alimentos ou água, uma vez que na produção de algumas dessas embalagens plásticas são empregados diversos compostos tóxicos como por exemplo o Bisfenol-A. Assim, quando manipulados de forma incorreta e submetidos a alguns fatores ambientais extremos como por exemplo altas temperaturas, tais componentes podem migrar para a água/alimento e acarretar reações adversas ao consumidor.

Na questão oito, perguntou-se aos participantes se eles conseguiam relacionar a pandemia do novo Coronavírus ao consumo mundial de plástico. Nas respostas, apenas oito alunos $(25,8 \%)$ relacionaram de forma correta o aumento ao consumo de plásticos influenciados pela pandemia. Dessa forma, 23 participantes $(74,2 \%)$ evidenciaram total desconhecimento dessa relação. O surgimento da Covid-19 fortaleceu a dependência dos plásticos por ser um produto versátil, resistente e capaz de gerar 
barreira contra patógenos. Com isso, seu consumo tem aumentado, principalmente na confecção de máscaras, luvas, macacões, protetores faciais, entre outros, confeccionados com plásticos (Flores, 2020).

Ainda no questionário um, as questões de nove a 13 buscaram refletir os conhecimentos dos discentes em relação às embalagens plásticas e seus impactos ao meio ambiente e à saúde humana. As questões nove e 10 foram novamente aplicadas no questionário dois após ao primeiro encontro e as questões de 11 a 13 foram novamente aplicadas no questionário três, após o segundo encontro. Por terem sido realizados em momentos distintos, os questionários possuem quantidades diferentes de participantes, e por isso as comparações serão realizadas por meio de porcentagens.

$\mathrm{Na}$ questão nove, pediu-se aos discentes que marcassem a resposta correta relacionada a vantagem no uso de plásticos ecológicos, sendo apresentadas as seguintes alternativas: a) dissolvem-se na água; b) absorvem água com facilidade; c) caramelizam por aquecimento e quebram; d) são digeridos por decompositores (alternativa correta); e) decompõem-se espontaneamente em contato com água e gás carbônico. No questionário um, marcaram a alternativa correta um total de 35,5\% dos alunos e no questionário dois, aplicado após a discussão desses pontos, o acerto foi de 65\%, como observado na Figura 3, evidenciando-se adequada a abordagem do conteúdo das embalagens plásticas por meio do ensino remoto.

Figura 3: Representação gráfica das respostas dos alunos em relação à vantagem do uso de plásticos ecológicos. As respostas obtidas no questionário um, são representadas pela letra $\mathrm{A}$ e as respostas obtidas no questionário dois por B. Em vermelho apontam-se as alternativas incorretas e em verde a alternativa correta para a referida questão.

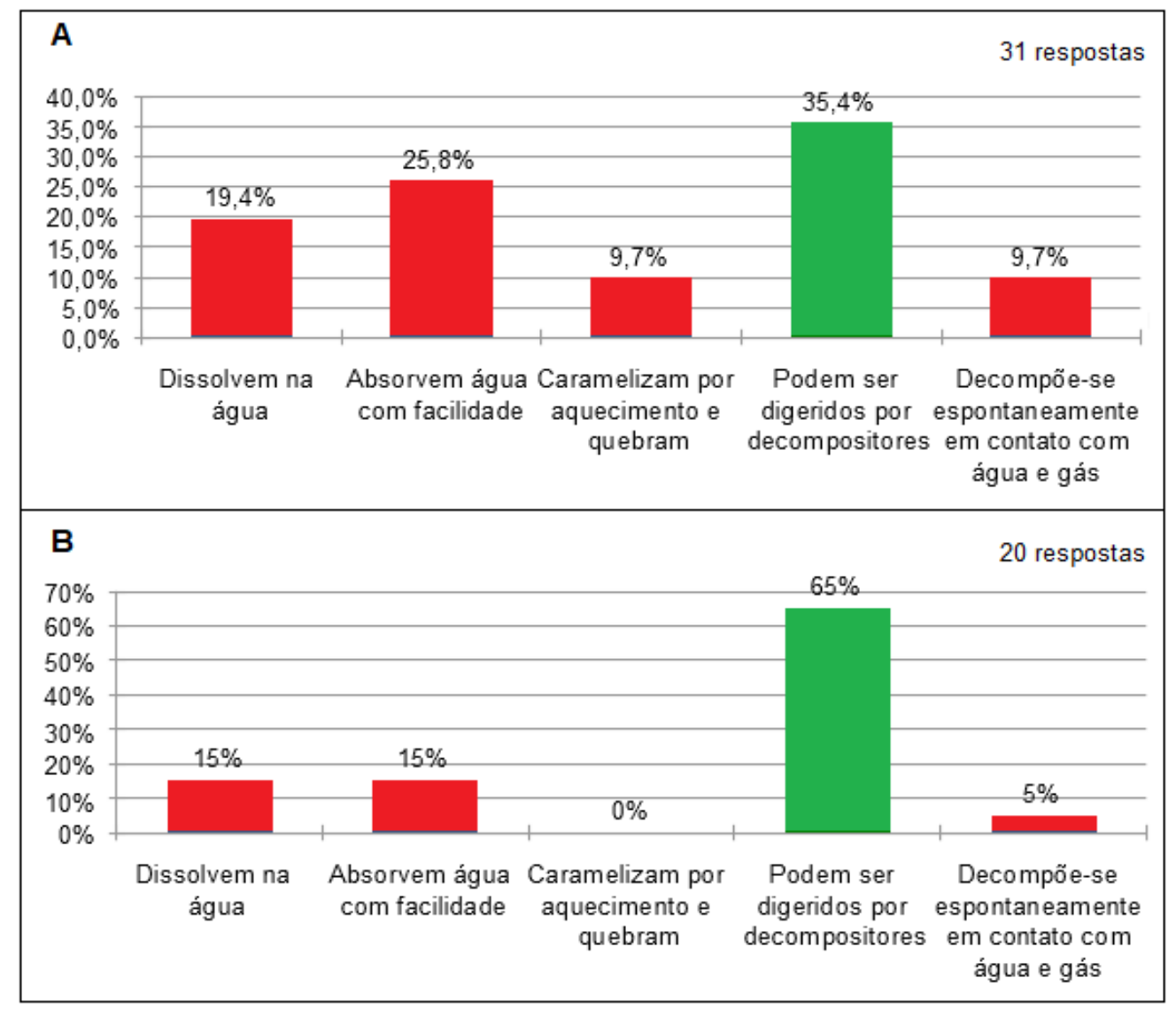

Fonte: Autores (2021).

Na questão 10, pediu-se aos discentes que marcassem a alternativa que indicavam somente polímeros naturais, sendo apresentadas as seguintes alternativas: a) celulose, plástico, poliestireno; b) amido, proteína, celulose (alternativa correta); c) 
amido, náilon, polietileno; d) plástico, PVC, teflon. No questionário um, marcaram a alternativa correta um total de 67,7\% dos alunos e no questionário dois, aplicado após a discussão desses pontos, o acerto foi de 85\%, como observado na Figura 4.

Ozório et al. (2015), ao realizarem uma pesquisa com 80 discentes do Ensino Médio de uma escola estadual do município de São Paulo, debateu o conteúdo polímeros e reciclagem, a fim de relacionar esses conteúdos trabalhados na escola com o cotidiano dos alunos. O debate realizado sobre os polímeros no cotidiano escolar estimulou o interesse dos alunos participantes e serviu como ferramenta de sensibilização ambiental.

Figura 4: Representação gráfica das respostas dos alunos em relação aos seus conhecimentos sobre polímeros naturais. As respostas obtidas no questionário um, são representadas pela letra A e as respostas obtidas no questionário dois por B. Em vermelho apontam-se as alternativas incorretas e em verde a alternativa correta para a referida questão.

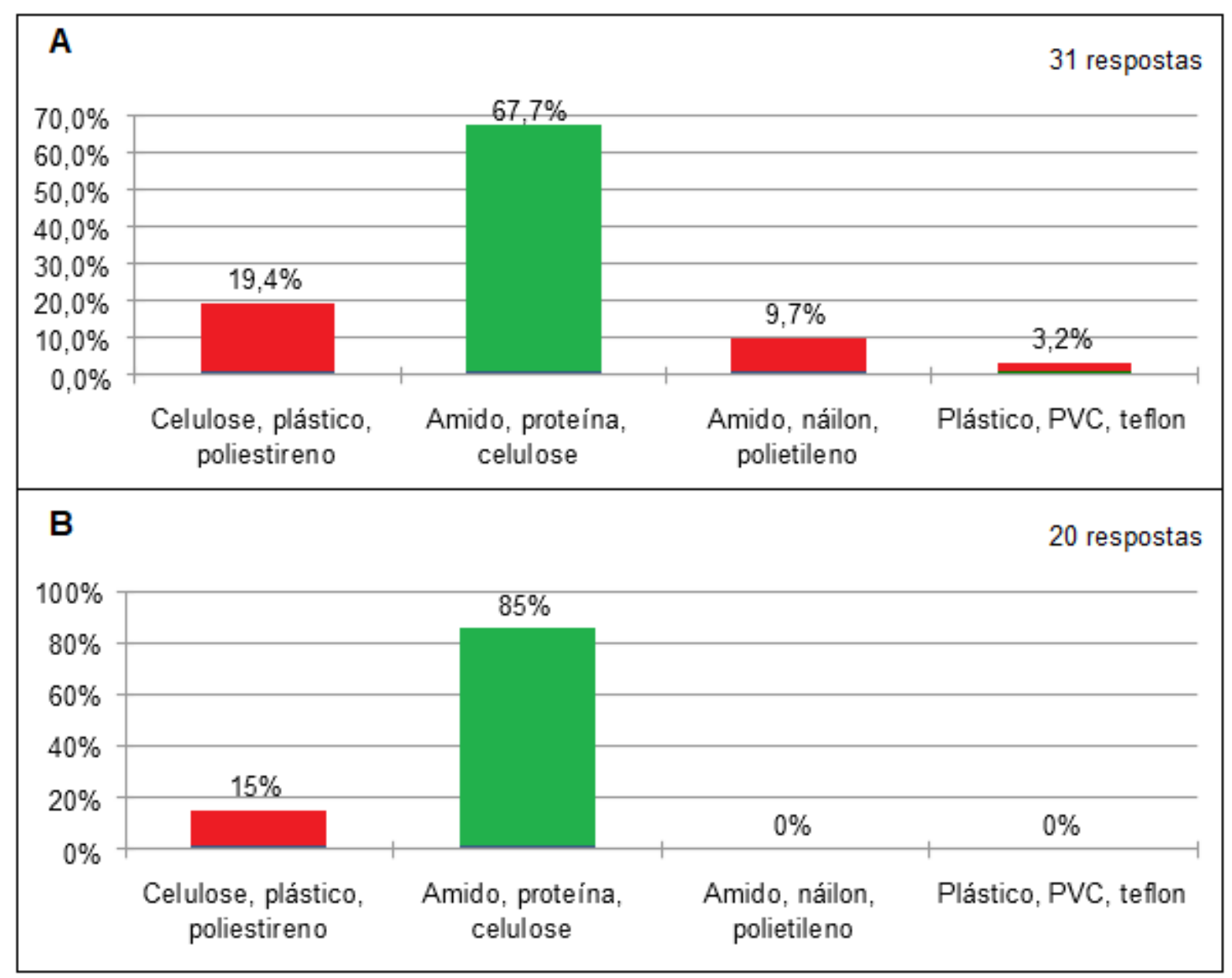

Fonte: Autores (2021).

Após o segundo encontro, aplicou-se o questionário três (respondido por 23 participantes) que repetia as questões $11 \mathrm{e}$ 12 do questionário um, com a adição de uma questão subjetiva. A pergunta 11 do questionário um pedia que os discentes marcassem a alternativa correta em relação aos compostos plásticos, sendo apresentadas as seguintes alternativas: a) temos que utilizá-los com precaução, pois por ser um produto natural, pode facilmente acabar; b) o uso de plásticos só traz pontos positivos para nossa sociedade; c) a reciclagem é um processo importante, pois permite a fabricação de novos plásticos a partir de sua matéria prima, o petróleo; d) os plásticos podem migrar para os alimentos e estar associados a várias doenças, como o câncer (alternativa correta); e) apesar da grande quantidade de plástico na Terra, por ser um composto facilmente degradado, possui 
fácil decomposição. Observou-se a partir das respostas que nenhum aluno acertou a pergunta no questionário um e que no questionário três o acerto foi de $38,8 \%$ dos alunos.

Na questão 10, pediu-se aos discentes que marcassem a alternativa que indicavam somente polímeros naturais, sendo apresentadas as seguintes alternativas: a) celulose, plástico, poliestireno; b) amido, proteína, celulose (alternativa correta); c) amido, náilon, polietileno; d) plástico, PVC, teflon. No questionário um, marcaram a alternativa correta um total de 67,7\% dos alunos e no questionário dois, aplicado após a discussão desses pontos, o acerto foi de 85\%, como observado na Figura 4.

Ozório et al. (2015), ao realizarem uma pesquisa com 80 discentes do Ensino Médio de uma escola estadual do município de São Paulo, debateu o conteúdo polímeros e reciclagem, a fim de relacionar esses conteúdos trabalhados na escola com o cotidiano dos alunos. O debate realizado sobre os polímeros no cotidiano escolar estimulou o interesse dos alunos participantes e serviu como ferramenta de sensibilização ambiental.

Figura 5: Representação gráfica das respostas dos alunos em relação aos seus conhecimentos sobre polímeros naturais. As respostas obtidas no questionário um, são representadas pela letra A e as respostas obtidas no questionário dois por B. Em vermelho apontam-se as alternativas incorretas e em verde a alternativa correta para a referida questão.

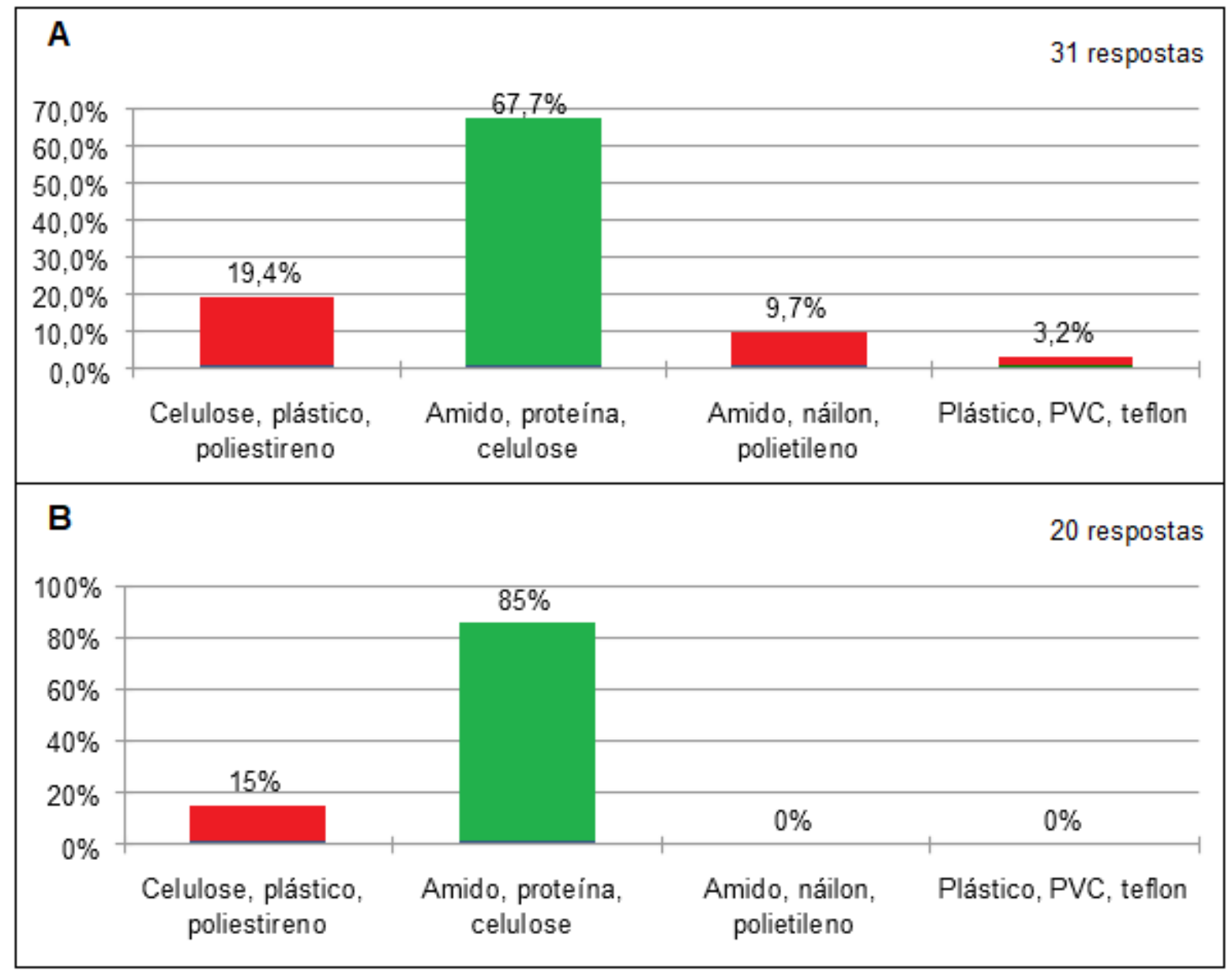

Fonte: Autores (2021).

Após o segundo encontro, aplicou-se o questionário três (respondido por 23 participantes) que repetia as questões $11 \mathrm{e}$ 12 do questionário um, com a adição de uma questão subjetiva. A pergunta 11 do questionário um pedia que os discentes marcassem a alternativa correta em relação aos compostos plásticos, sendo apresentadas as seguintes alternativas: a) temos que utilizá-los com precaução, pois por ser um produto natural, pode facilmente acabar; b) o uso de plásticos só traz pontos positivos para nossa sociedade; c) a reciclagem é um processo importante, pois permite a fabricação de novos plásticos a partir de sua 
matéria prima, o petróleo; d) os plásticos podem migrar para os alimentos e estar associados a várias doenças, como o câncer (alternativa correta); e) apesar da grande quantidade de plástico na Terra, por ser um composto facilmente degradado, possui fácil decomposição. Observou-se a partir das respostas que nenhum aluno acertou a pergunta no questionário um e que no questionário três o acerto foi de $38,8 \%$ dos alunos.

\section{Considerações Finais}

A partir das respostas dos participantes, apontamos que a Educação Ambiental ainda é trabalhada de forma incipiente, pouco prática e desintegrada das diversas disciplinas que compõem a Educação Básica, em desacordo com o que preconiza a legislação vigente. Destacamos também que, apesar das carências evidenciadas, os discentes demonstram conhecimentos diversos relacionados aos riscos associados ao uso de embalagens plásticas, ainda que a maioria não consiga relacionar o aumento desses riscos ambientais com a pandemia do novo coronavírus.

A pesquisa evidencia um desconhecimento generalizado quanto aos riscos das embalagens plásticas à saúde humana, o que exige um maior aprofundamento do tema na Educação Básica, bem como na sociedade em geral. Apesar das barreiras impostas pela pandemia para esses e outros debates em Educação Ambiental, ressaltamos que o ensino remoto se mostrou como uma valiosa ferramenta, caracterizando-se como um espaço que permite discussões, aprofundamentos e integração dos temas em Educação Ambiental às disciplinas escolares. Apontamos também a necessidade de novos estudos que busquem discutir a temática dos compostos plásticos de forma interdisciplinar com ênfase aos seus impactos à vida e à saúde humana.

\section{Referências}

Antqueves, L. M., Bosa, C. R., \& Dubiaski-Silva, J. A. (2015). A Educação Ambiental e atividades lúdicas: um incentivo a mudança de hábitos na geração de lixo. Revista Monografias Ambientais, 14(2), 183-192. https://periodicos.ufsm.br/remoa/article/view/18806/pdf

Araújo, D. P., Rohde, C., \& Castro, I. F. A. (2020). The perception of Uruçuiense population regarding to the use of plastic packaging and the effects on the environment and human health. Research, Society and Development, 9(11), 1-22. https://rsdjournal.org/index.php/rsd/article/view/9770

Araújo, M. C. B., \& Silva-Cavalcanti, S. J. (2016). Dieta indigesta: milhares de animais marinhos estão consumindo plásticos. Revista Meio Ambiente e Sustentabilidade, 10(5), 1-8. https://www.revistasuninter.com/revistameioambiente/index.php/meioAmbiente/article/view/511

Azeredo, D. G., Gass, V. L., Milanez, F., \& Pizzato, A. C. (2017). Evidências em relação aos riscos à saúde pelo uso do plástico em embalagens alimentícias. Ciência \& Saúde, 10(3), 184-191. https://www.researchgate.net/publi

,]loy55cation/318799561_Evidencias_em_relacao_aos_riscos_a_saude_pelo_uso_do_plastico_em_embalagens_alimenticias

Brasil. Constituição da República Federativa do Brasil de 1999. (1999). Brasília, Presidência da República. http://www.planalto.gov.br/ccivil_03/leis/19795.htm

Brasil. Ministério da Educação (1997). Parâmetros Curriculares Nacionais para o Ensino Fundamental. Brasília, 1997. http://portal.mec.gov.br/seb/arquivos/pdf/livro01.pdf

Carneiro, B. S., Oliveira, M. A. S., \& Moreira, R. F. (2016). Educação Ambiental na escola pública. Revista Brasileira de Educação Ambiental (RevBEA), 11(1), 25-36. https://periodicos.unifesp.br/index.php/revbea/article/view/1893

Cruz, B. S. M., Souza, M. L., \& Freitas, A. B. R. (2020). Reutilização de plásticos: uma forma de articular a Educação Ambiental e o Ensino de polímeros através de uma feira de ciências. Revista Eletrônica Perspectivas da Ciência e Tecnologia, 12(1), 103-121. https://revistascientificas.ifrj.edu.br/revista/index.php/revistapct/article/view/1645

Ferreira, M., \& Loguecio, R. Q. (2014). A análise de conteúdo como estratégia de pesquisa interpretativa em educação em ciências. Revista de Educação, Linguagem e Literatura, 6(2), 33-49. https://lume.ufrgs.br/bitstream/handle/10183/142567/000994515.pdf?sequence=1\&isAllowed=y

Flores, P. (2020). The issue of plastic use during the Covid-19 pandemic. South Sustainability, 1(2). https://revistas.cientifica.edu.pe/index.php/southsustainability/article/view/733

Giassi, M. G., Dajori J. F., Machado, A. C., \& Martins, C. M. (2016). Ambiente e Cidadania: educação Ambiental nas escolas. Revista de Extensão, 1(1), 2432. http://periodicos.unesc.net/revistaextensao/article/view/2461

Menezes, J. B. F., Nogueira, A. P., Paixão, G. C., Ponte, F. L., \& Pereira, L. M. G. (2018). Conceitos, práticas de Educação Ambiental e formação cidadã na escola. Ambiente e Educação - Revista de Educação, 23(1), 185-197. https://periodicos.furg.br/ambeduc/article/view/6620

Oliveira, T. M. R., \& Amaral, C. L. C. (2019). Discutindo conceitos de Educação Ambiental com professores em uma escola pública de São Paulo. Revista Ensino, Saúde e Ambiente, 12(2), 140-155. https://periodicos.uff.br/ensinosaudeambiente/article/view/27174 
Research, Society and Development, v. 10, n. 9, e44010918314, 2021

(CC BY 4.0) | ISSN 2525-3409 | DOI: http://dx.doi.org/10.33448/rsd-v10i9.18314

Ozório, M. S., Souza-Filho, M. P., Alves, N., \& Job, A. E. (2015). Promovendo a conscientização ambiental: resultados de uma pesquisa realizada com alunos do ensino médio sobre polímeros, plásticos e processos de reciclagem. Revista Brasileira de Educação Ambiental, 10(2), 11-24. https://periodicos.unifesp.br/index.php/revbea/article/view/1927

Pacheco, F. F., Barreto, J. S., Silva, R. B., Hermogeni, V. C., Raggi, D. G., \& Guisso, L. F. (2020). Sustentabilidade: a percepção desse conceito em uma escola municipal do sul do Espírito Santo. Revista Científica Multidisciplinar Núcleo do Conhecimento, 7(5), 05-25. https://www.researchgate.net/publication/341536090_Sustentabilidade_A_percepcao_desse_conceito_em_uma_Escola_Municipal_do_sul_do_Espirito_Santo

Pereira, S. P., Shitsula, D. M., Parreira, F. J., \& Shitsuka, R. (2018). Metodologia da Pesquisa Científica (1. ed.). Santa Maria, RS: UAB/NTE/UFSM. https://repositorio.ufsm.br/bitstream/handle/1/15824/Lic_Computacao_Metodologia-Pesquisa-Cientifica.pdf?sequence=1

Prata, J. C., Costa, J. P., Lopes, I., Duarte, A. C., \& Rocha-Santos, T. (2020). Environmental exposure to microplastics: An overview on possible human health effects. Science of The Total Environment, 702(1), 1-9. https://www.sciencedirect.com/science/article/pii/S0048969719344468?casa_token=D6wrWI44OkAAAAA:Vn8x-kMAMcwQQRYtsSHmYJyQlvrVUsg7PI2kMgFJhReh-rlYHEPHG8qlY2UEgr4RN57DRdBWyA

Santos F. A. T., Rodrigues, E. C. V., \& Lima, E. M. (2019). Educação ambiental e alimentar a curto prazo através do ensino de ciências. Ensino, Saúde e Ambiente, 11(3), 218-240. https://periodicos.uff.br/ensinosaudeambiente/article/view/21595/16069

Silva, A. H. D., \& Pereira, J. L. G. (2020). Educação ambiental na "Cidade do Aço": Município de Volta Redonda - Rio de Janeiro. Revista Científica Multidisciplinar Núcleo do Conhecimento, 3(4), 108-118. https://www.nucleodoconhecimento.com.br/educacao/cidade-do-aco

Silva, F. D. (2019). Gestão e Educação Ambiental: uma relação meio ambiente e saúde. Revista Saúde e Meio Ambiente, 9(2), 100-114. https://periodicos.ufms.br/index.php/sameamb/article/view/7721 